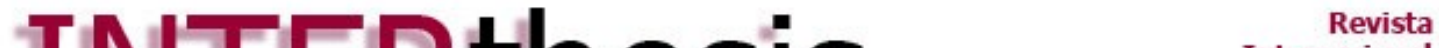 INTERthesis No 01

\section{INSTRUÇÕES AOS AUTORES}

1. A INTERthesis - Revista Internacional Interdisciplinar, publicada pelo Programa de Pós-Graduação Interdisciplinar em Ciências Humanas da UFSC, recebe artigos inéditos, com temática interdisciplinar, estabelecendo pontes entre disciplinas principalmente em áreas temáticas tais como:

- Condição Humana na Modernidade,

- Estudos de Gênero e

- Sociedade e Meio Ambiente

Serão aceitas contribuições nas seguintes modalidades:

Artigo: contribuição destinada a divulgar resultados de pesquisa de natureza empírica, experimental ou conceitual (mínimo de 10 e máximo de 30 páginas, excluindo títulos, resumos, tabelas, figuras e referências).

Revisão: avaliação crítica sistematizada da literatura sobre determinado assunto; deve-se citar o objetivo da revisão, especificar (em métodos) os critérios de busca na literatura e o universo pesquisado, discutir os resultados obtidos e sugerir estudos no sentido de preencher lacunas do conhecimento atual (mínimo de 10 e máximo de 30 páginas, excluindo títulos, resumos, tabelas, figuras e referências).

Ensaio: reflexão circunstanciada, com redação adequada ao escopo de uma publicação científica, com maior liberdade por parte do autor para defender determinada posição, que vise a aprofundar a discussão ou que apresente nova contribuição/abordagem a respeito de tema relevante (mínimo de 10 e máximo de 30 páginas, excluindo títulos, resumos, tabelas, figuras e referências).

Resenha: análise crítica sobre livro publicado nos últimos dois anos (até 8 páginas, com as mesmas configurações que se solicita ao texto, incluindo referência bibliográfica completa no cabeçalho. Caso se faça menção a outras referências as mesmas devem ser incluídas no final do texto num item a parte como Referências).

2. Artigo submetido por aluno(a) de pós-graduação (Mestrado e/ou Doutorado) somente será aceito se escrito em co-autoria com o(a) Orientador(a), conforme sugere a Coordenação de Aperfeiçoamento de Pessoal de Nível Superior - CAPES.

3. Todos os artigos são apreciados por dois avaliadores, através do sistema Blind Review, ou seja, avaliação cega.

4. Os originais poderão ser:

- Aceitos na íntegra, sem restrições;

- Aceitos na íntegra, com algumas alterações ou correções obrigatórias ou;

- Rejeitados. 
5. É de responsabilidade do(s) autor(es) promover(em) as devidas revisões gramaticais no texto encaminhado bem como se preocupar com a obtenção de autorização de direitos autorais com relação ao uso de imagens, figuras, tabelas, métodos etc. junto a outros autores ou editores, quando for o caso.

6. Quando as alterações forem referentes apenas a aspectos gramaticais, ortográficos e de ordem normativa, com vistas a manter a homogeneidade da publicação, editores e editores assistentes tem o direito de fazer as modificações necessárias, respeitando o estilo do autor. Nos demais casos, o autor reformulará o texto conforme o que for solicitado retornando-o no prazo máximo de 30 dias para nova avaliação.

7. Os artigos e demais trabalhos publicados na INTERthesis, passam a ser propriedade da revista. A impressão, total ou parcial, fica sujeita à expressa menção da precedência de sua publicação citando-se a edição, data da publicação e endereço eletrônico.

8. Os textos podem ser apresentados em três línguas: português, espanhol ou inglês.

9. Os artigos em língua portuguesa deverão ser redigidos conforme a norma de apresentação de artigos da Associação Brasileira de Normas Técnicas - ABNT NBR6022 de maio de 2003.

10. Para os artigos em língua espanhola e inglesa deverão ser utilizadas as normas ISO equivalentes.

11. Submissão eletrônica: Os artigos deverão ser remetidos via plataforma em http://www.periodicos.ufsc.br/index.php/interthesis/about/submissions\#onlineSubmissio ns

12. Se o autor já estiver cadastrado, é necessário somente fazer o Login e iniciar os passos para a submissão do trabalho. Se ainda não estiver cadastrado é necessário usar o link Não está cadastrado? Cadastre-se no sistema http://www.periodicos.ufsc.br/index.php/interthesis/user/register, preencher o formulário e completar as informações.

13. Em seguida, utilize o link Autor e inicie o processo de submissão do artigo. São cinco passos, lembre de salvar no final de cada etapa:
a) Início
b) Inclusão de Metadados
c) Transferência do Manuscrito
d) Transferência de Documentos Suplementares
e) Confirmação. 
14. Anonimato - solicita-se que antes de submeter o texto, se retire o(s) nome(s):

- da autoria do arquivo enviado;

- no corpo do texto do artigo;

- nas Referências, caso haja menção de artigo, dissertação, tese ou qualquer outro trabalho científico de autoria do(s) nome(s) do(s) autor (es) e que identifique o manuscrito.

O nome do(s) autor(es) devem sempre ser substituído(s) pela expressão "NOME DO AUTOR" conforme exemplo abaixo:

\section{Nas Referências:}

NOME DO AUTOR. Introdução à pesquisa em ciências sociais: a pesquisa qualitativa em educação. São Paulo: Atlas, 2005.

NOME DO AUTOR. Adversidades no trabalho: a condição de ser trabalhador no sistema de produção flexível na indústria automobilística brasileira. 2006. 226 f. Tese (Doutorado em Ciências Humanas) Programa de Pós-Graduação Interdisciplinar em Ciências Humanas, Universidade Federal de Santa Catarina. Florianópolis, 2006.

\section{No texto:}

Uma análise atrelada teoricamente à discussão da apropriação da subjetividade do trabalhador em face das condições adversas de trabalho estabelecidas no sistema flexibilizado e dos resultados obtidos pela observação dos relatos dos trabalhadores falando de sua realidade. (Nome do autor, 2006)

15. Características gerais do texto:

O texto submetido deve ser digitado em Word 7.0 (ou superior)

- Espaço 1,5

- Alinhamento justificado

- Letra tipo Arial, corpo 12

- Papel em formato A4

- Margens superior/inferior $=3,0$

- Margens direita e esquerda $=2,0$

- Parágrafo recuo primeira linha $=1,25$ 
16. O texto submetido deve ser composto na seguinte seqüência:

a) Títulos:

i. No cabeçalho, o título deve ficar em alinhamento à esquerda, justificado e espaçamento entre linhas simples;

ii. Fonte Arial 12, em negrito e caixa alta;

iii. Ordem de apresentação dos títulos: $1^{\circ}$ ) em português, $2^{\circ}$ ) inglês e $3^{\circ}$ ) espanhol;

b) Resumo/Abstract/Resumen:

i. Deve ser claro e conciso num único parágrafo, contendo objetivo, metodologias, resultados e conclusões;

ii. Fonte Arial 12, justificado e espaçamento simples;

iii. No mínimo 100 e no máximo 250 palavras;

iv. Ordem de apresentação dos resumos: $1^{\circ}$ )português, $2^{\circ}$ ) inglês e $3^{\circ}$ ) espanhol, nesta;

c) Palavras-chave, Keywords, Palabras-clave:

i. Fornecer de 03 a 05 palavras-chave que melhor representem o assunto do artigo.

ii. As palavras-chave devem ser separadas por ponto e vírgula e somente a primeira palavra deve iniciar com letra maiúscula.

d) Corpo do texto do artigo:

i. Em espaço $1,5 \mathrm{~cm}$;

ii. Alinhamento justificado;

iii. Fonte Arial, 12;

iv. Parágrafo recuo primeira linha de $1,25 \mathrm{~cm}$.

e) As citações diretas com até três linhas devem estar contidas entre aspas duplas.

Exemplo:

Carvalho e Schmitz (1990, p.149) afirmam que "até os anos 70 os princípios do fordismo guiaram internacionalmente a administração na indústria automobilística e em outras indústrias de produção em massa. [...]" 
f) As citações diretas com mais de três linhas devem ser destacadas:

i. com recuo de $4 \mathrm{~cm}$ da margem esquerda;

ii. em fonte 10;

iii. espaçamento antes e depois de 12 pontos;

iv. entre linhas 'Exatamente' 14 e sem aspas.

Exemplo:

São abundantes os sinais e marcas de modificações radicais em processos de trabalho, hábitos de consumo, configurações geográficas e geopolíticas, poderes e práticas do Estado etc. No Ocidente, ainda vivemos uma sociedade em que a produção em função de lucros permanece como princípio organizador básico da vida econômica. Portanto, precisamos de alguma maneira representar todos os grandes eventos ocorridos desde a primeira grande recessão do pós-guerra, em 1973, maneira que não perca de vista o fato de as regras básicas do modo capitalista de produção continuarem a operar como forças plasmadoras invariantes do desenvolvimento histórico-geográfico (HARVEY, 2002, p.117).

g) Nas citações ao longo do texto não se deve esquecer do 'anomimato' solicitado no item 9 supracitado.

h) As citações no corpo do texto deverão ser redigidas de acordo com a NBR10520 ou norma ISO equivalente, observando o solicitado no item 9 supracitado.

i) Utilizar preferencialmente o sistema autor-data.

\section{Exemplos de Citação}

\section{Com um autor:}

- A ironia seria assim uma forma implícita de heterogeneidade mostrada, conforme a classificação proposta por Authier-Reiriz (1982).

- "[...] para que tenha lugar a produç̧ão de degenerados, quer physicos quer moraes, misérias, verdadeiras ameaças à sociedade." (SOUTO,1916, p. 46).

\section{Com dois ou três autores:}

- "Não se mova, faça de conta que está morta." (CLARAC; BONNIN, 1985, p. 72).

- Merrian e Caffarella (1991) observam que a localização de recursos tem (...).

Com mais de três autores:

- Santos et al (2002, p.36) argumentam que o "desenvolvimento [...]".

- "Desenvolvimento sustentável [...]" (SANTOS et al., 2002, p.36). 
Citação de outra citação: deve ser evitado, quando possível.

- Leedy (1988 apud RICHARDSON, 1991, p. 417) compartilha deste ponto de vista ao afirmar "os estudantes estão enganados quando acreditam que eles estão fazendo pesquisa [...]".

- "O campo [...]" (BOURDIEU, 1999, p.75 apud OLIVEIRA, 2007, p.131)

- "[...] o viés organicista da burocracia estatal e o antiliberalismo da cultura política de 1937, preservado de modo encapuçado na Carta de 1946." (VIANNA, 1986, p. 172 apud SEGATTO, 1995, p. 214-215).

Mesmo autor com várias obras:

\section{Anos diferentes:}

- (REESIDE, 1927) - (REESIDE, 1928)

Mesmo ano: acrescenta-se letra minúscula após o ano.

- (REESIDE, 1927a) - (REESIDE, 1927b)

\section{Citação indireta:}

- Merrian e Caffarella (1991) observam que a localização de recursos tem um papel crucial no processo de aprendizagem autodirigida.

\section{Documentos oficiais:}

- "O mecanismo proposto para viabilizar esta concepção é chamado Contrato de Gestão, que conduziria à captação de recursos privados como forma de reduzir os investimentos públicos no ensino superior" (BRASIL, 1995, p. 6).

17. Se possível, não usar notas de rodapé, sendo imprescindível a numeração deve ser arábica e seqüencial, e situada ao fim da página.

\section{Referências:}

i. Deverão ser redigidas de acordo com a NBR6023 ou norma ISO equivalente.

ii. Devem ser referenciadas apenas as referências utilizadas no corpo do texto;

iii. As referências são alinhadas somente a margem esquerda do texto e de forma a se identificar individualmente cada documento, em espaço simples e separadas entre si por espaço duplo;

iv. Utilizar o recurso tipográfico negrito para destacar o elemento título em todas as referências. 
Ver exemplos das Referências a seguir:

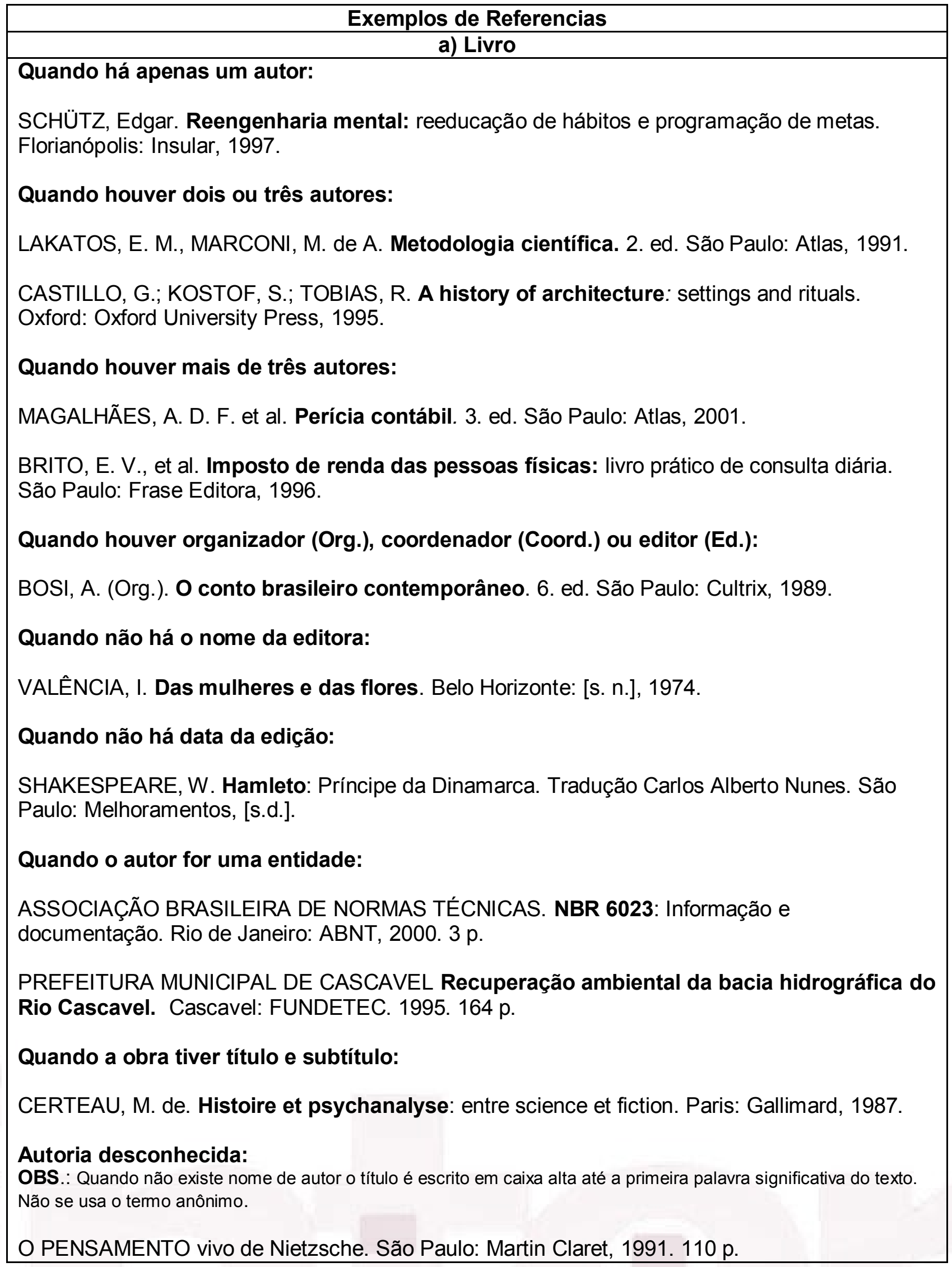


Partes de livro sem autoria especial:

b) Capítulo de Livro

LIMA, L. de O. Ativação dos processos didáticos na escola secundária. In: secundária moderna: organização, métodos e processos. Rio de Janeiro: ForenseUniversitária, 1976. cap. 12, p. 213-234.

Partes de livro com autoria especial:

HORTA, J. S. B. Planejamento educacional. In: MENDES, Dumerval Trigueiro (org.). Filosofia da Educação Brasileira. Rio de Janeiro: Civilização Brasileira, 1991. p. 195-239.

\section{c) Artigo em Periódico}

BORTOLETTO, M. C. O que é ser mãe? A evolução da condição feminina na maternidade através dos tempos. Viver Psicologia, São Paulo, v. 1, n. 3, p. 25-27, out. 1992.

MARISOL, G. R. Relação humana no emprego de grupos de qualificação empresarial. RevistaLatinoamericana de Comunicação nas Relações Humanas, Buenos Aires, v. 17. n. 5, p. 23-26, jan. 1996.

ESPOSITO, I. et al. Repercussões da fadiga psíquica no trabalho e na empresa. Revista Brasileira de Saúde Ocupacional, São Paulo, v.8, n.32, p.37-45, out./dez. 1979.

RAUD, C. Análise crítica da sociologia econômica de Mark Granovetter: os limites de uma leitura do mercado em termos de redes e imbricação. Política \& Sociedade, Florianópolis, n.6, p.59-82, abr. 2005.

\section{Monografia}

\section{d) Monografia, Dissertação e Tese}

MEDEIROS, J. B. Alucinação e magia na arte. 1993. 86 f. Monografia (apresentada ao final do curso de pós-graduação stricto sensu em Letras) - Faculdade de Filosofia, Letras e Ciências Humanas, Universidade de São Paulo, São Paulo.

\section{Dissertação de Mestrado}

RODRIGUES, M. V. Qualidade de vida no trabalho. 1989. 180 f. Dissertação (Mestrado em Administração) - Faculdade de Ciências Econômicas, Universidade Federal de Minas Gerais, Belo Horizonte, 1989.

Tese

FANTUCCI, I. Contribuição do alerta, da atenção, da intenção e da expectativa temporal para o desempenho de humanos em tarefas de tempo de reação. 2001. $130 \mathrm{f}$. Tese (Doutorado em Psicologia) - Instituto de Psicologia, Universidade de São Paulo, São Paulo, 2001. 


\section{Encontro Anual}

\section{e) Eventos}

GONÇALVES, M.;PEIXOTO, D. F. Desenvolvimentos na Produção de Chapas VDS (Vibration Damping Sheet). In: CONGRESSO ANUAL DA ABM, 56., 2001, Belo Horizonte. Anais... São Paulo: Perspectiva, 2001. p. 49-60.

Artigo de Internet com autor:

\section{f) Internet}

BARBOSA, Lucia Martins et al. A representação social do professor sob o ponto de vista do aluno. Revista Aprender Virtual, Marília, dez. 2003. Disponível em:

<http://www.aprendervirtual.com/ver_noticia.php?codigo=32>. Acesso em: 2 fev. 2004.

\section{Artigo de Internet sem autor especial:}

CIÊNCIA DA INFORMAÇÃO, Brasília, v.26. n.3, 1997. Disponível em :

<http://www.ibict.br/cionline/>. Acesso em: 19 maio 1998.

\section{Livro em meio eletrônico:}

ALVES, C. Navio negreiro. [S.I.]: Virtual Books, 2000. Disponível em:

<http://www.terra.com.br/virtualbooks/port//port/navionegreiro.htm>. Acesso em: 05 mar. 2004

\section{Simpósios e Congressos em meio eletrônico:}

CONGRESSO DE INICIAÇÃO CIENTÍFICA DA UFPE, 4., 1996, Recife. Anais eletrônicos... Recife: UFPe, 1996. Disponível em: <http://www.propesq.ufpe.br/anais/anais.htm>. Acesso em: 21 jan. 1997.

19. O(s) conteúdo(s) do(s) trabalho(s) é (são) de responsabilidade exclusiva dos(as) autores(as).

Universidade Federal de Santa Catarina - UFSC

Centro de Filosofia e Ciências Humanas - CFH

Programa de Pós-Graduação Interdisciplinar em Ciências Humanas - PPGICH

Editores: Selvino Assmann e Silmara Cimbalista

http://www.periodicos.ufsc.br/index.php/interthesis/index

E-mail: interthesis@cfh.ufsc.br

R. Inter. Interdisc. INTERthesis, Florianópolis, 2009. 